\title{
Development of polyindole/tungsten carbide nanocomposite-modified electrodes for electrochemical quantification of chlorpyrifos
}

\author{
Pragati Joshi $^{1}$ - Sameena Mehtab ${ }^{1}$ - M. G. H. Zaidi ${ }^{1} \cdot$ Tanvi Tyagi $^{1} \cdot$ Anjali Bisht $^{1}$
}

Received: 5 September 2019 / Accepted: 11 December 2019 / Published online: 24 December 2019

(c) The Author(s) 2019

\begin{abstract}
The present investigation deals with the development of a novel polymer nanocomposite (PNCs) electrodes for simple, selective and sensitive detection of chlorpyrifos (CHL). PNCs were developed using surfactant facilitated polymerization of indole using different concentrations (wt\%) of WC ranging 5-30. Formation of PNCs was ascertained through diversified analytical methods. Electrodes were derived from PNCs over stainless steel substrate for electrochemical quantification of CHL. With concentration of WC, the DC conductivity $\left(10^{-2} \times \mathrm{S} / \mathrm{cm}\right)$ of electrodes was increased ranging 3.54-0.75 at $313 \mathrm{~K}$. Electrochemical impedance spectroscopy reveals well stability of electrodes in phosphate buffer (PBS, $0.1 \mathrm{M})$ at $\mathrm{pH}$ 7.4. The performance of electrodes towards detection and quantification of CHL was investigated through square wave voltammetry. Study reveals that detection and quantification of CHL were dependent on concentration of WC in nanocomposites. Square wave voltammetry reveals that the electrode derived from PNCs with $5 \mathrm{wt} \%$ of WC has rendered highest limits of detection and quantification of CHL $\left(10^{-8} \mathrm{~mol} / \mathrm{L}\right)$ up to 5.94 and 18 . This work describes a viable method of preparation of synergistic blend of WC in PIN matrix having high electrical conductivity, rapid electron shift, huge surface area and enhanced stability for fast and précised electrochemical detection of CHL.
\end{abstract}

Sameena Mehtab smiitr@gmail.com

1 Department of Chemistry, College of Basic Sciences and Humanities, G.B. Pant University of Agriculture and Technology, U.S Nagar, Pantnagar, Uttarakhand 263145, India 


\section{Graphic abstract}
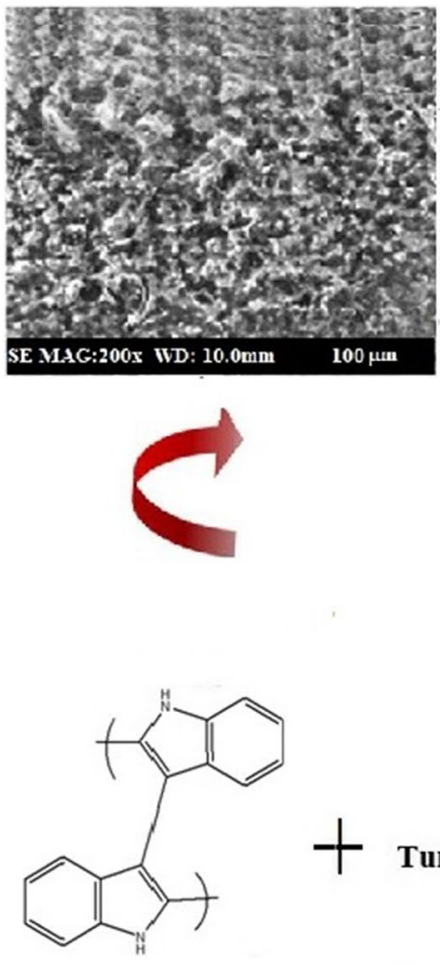

Polyindole

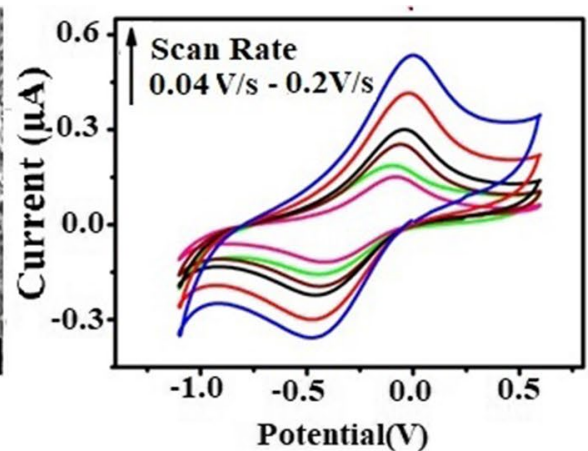<smiles></smiles>

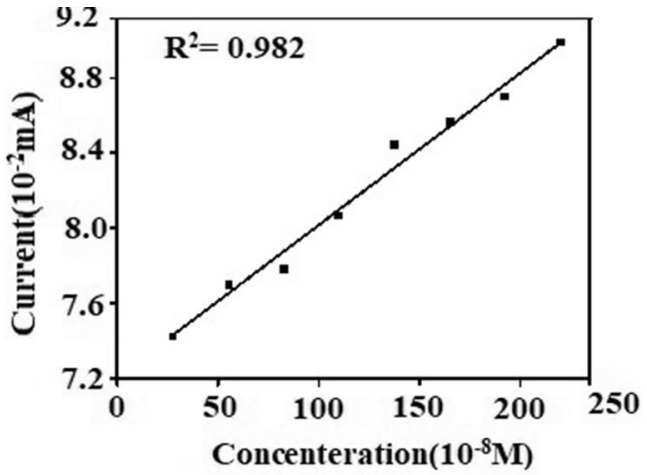

Chlorpyrifos

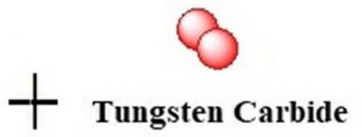

Tungsten Carbide

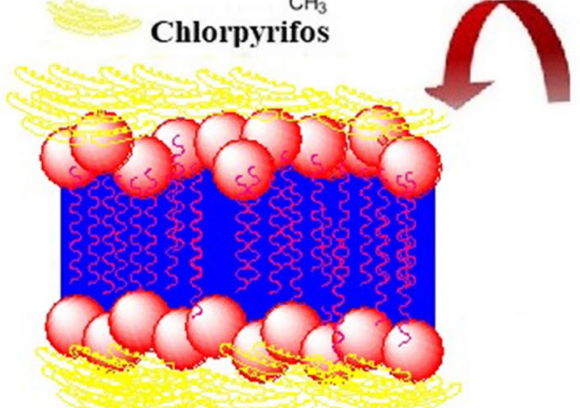

CHL sensing over PNCs coated electrode

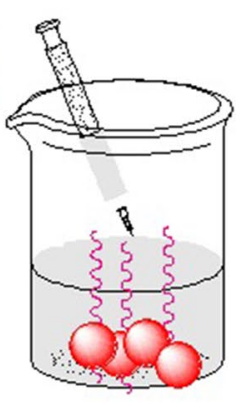

PNCs

Keywords Nanocomposite $\cdot$ Chlorpyrifos $\cdot$ Electrochemical sensing $\cdot$ Cyclic voltammetry $\cdot$ Square wave voltammetry Quantification

\section{Introduction}

Organophosphates (OPs) are the esters, amide and thiol derivatives of phosphorous-based acid [1-3]. Low water solubility and high absorption coefficient impart long residual effect of OPs in soil. This allows the entry of OPs into food chain causing neurotoxicity to animals due to irreversible inhibition of acetyl cholinesterase (AChE) [4-6]. For such reasons, development of novel methods of detection of OPs has been the subject of investigation over decades. In this context, various chromatographic, mass spectrometric, electrophoretic, [7-10] and electrochemical [11-14] methods were developed for detection of OPs.

Chlorpyrifos (CHL, o,o-diethyl-o-(3,5,6-trichloro2-pyridinyl)phosphorothioate) belongs to the family of OPs, used for crop protection as insecticide and nematicide. Realizing health hazards imposed over ecosystem, there has been growing concern on advancement of selective, precise, rapid and reliable approach for CHL detection. In this context, the quantification of CHL through chromatographic $[15,16]$ and electrochemical $[17,18]$ methods has been well established.
Among such methods, based on chromatography involves expensive instrumentation, multiple steps of preparation, immobilization and regeneration of samples, large consumption of chemicals, time along with low sensitivity of detection $[19,20]$. However, electrochemical methods, specially based on square wave voltammetry (SWV), have received immense acceptance because of reasonable simplicity, high sensitivity and potential towards selective quantification of detection of CHL down to ng level [21-23]. SWV has also been used for detection of a wide range of OPs over nanocompositemodified GCE. Nanocomposites employed for electrochemical detection of OPs were parathion [24-28], malathion [29, $30]$ and paraoxon $[31,32]$. The nanocomposites employed for modification of GCE for OPs detection were zeolite [24], $\mathrm{ZrO}_{2}$ [25], Au/Graphene [26, 27], $\mathrm{ZrO}_{2}$ [28], SWNT/GO [29], MWCNT [30], Au/Pt [31] and $\mathrm{ZrO}_{2} / \mathrm{MWCNT}$ [32]. The nanomaterials used for detection of CHL were graphene [17], MWCNT [33-35], with nano- $\mathrm{TiO}_{2}$ [36], carbon nitride [37], ferrocene [38], $\mathrm{CuO}$ [39]. Conducting polymers have been used as such or in the form of their nanocomposites for detection of CHL through SWV [24, 30]. Literature revealed 
that a wide range of nano-composites has been employed for the detection of various OPs [24-32], including CHL [33-39]. To the best of our knowledge, no records are available on electrochemical detection of CHL over PNCs derived through immobilization of WC into PIN matrix.

Recently, conducting polymer-based nanostructures containing carbonaceous and inorganic nanomaterials have been used in electrochemical studies for various applications [40-44]. Amongst the family of conducting polymers, polyindole (PIN) has an edge over other, due to its sustained polymerization, high electrical conductivity, low manufacturing cost and less toxicity [45-49]. Sensing behavior of PIN is modified through doping transition metal-based dopants that chanalize the electron transfer mechanism through polaron formation [50]. In this context, common dopants employed for PIN are gold [51], oxides of zinc and nickel [52], tin [53], iron [54], vanadium [55] and copper [56]. Nanocomposite of titanium carbide and poly(3,4-ethylenedioxythiophene) were prepared as an alternative electrocatalyst for dye-sensitized solar cell applications [57-60]. The present work proposed a novel and economical sensor for the trace level electrochemical detection of CHL, by utilizing WC-doped PIN nanocomposite.

\section{Materials and methods}

\section{Materials}

CHL with purity ( $\geq 99.9 \%$ ), chlorosulfonic acid ( $>99 \%$ ), indole $(>99 \%)$ and cetyltrimethylammonium bromide (CTAB) (>99\%) were purchased from Sigma-Aldrich. Rest of the chemicals and solvents (purity $>98 \%$ ) were indigenously procured and used without further purification. Phosphate buffer $(\mathrm{pH} 7.4,0.1 \mathrm{M})$ and stock solution of CHL $\left(1.0 \times 10^{-4}\right.$ $\mathrm{M})$ were prepared through traditional methods. In the present results, bare electrode, $5 \mathrm{wt} \%$ and $30 \mathrm{wt} \%$ PNCs-coated electrode are represented by [I], [II] and [III], respectively.

\section{Preparation of nanocomposites}

PIN along with various wt $\%$ fractions of WC ranging 5-30 [I-III] was synthesized by cationic surfactant method placed in two-necked glass reaction vessel implemented with mechanical stirrer and dropping funnel. To this, CTAB $\left(2.7 \times 10^{-3} \mathrm{~mol}\right)$ was added and the content was stirred @ $500 \mathrm{rpm}$ over $6 \mathrm{~h}$. To initiate the polymerization process, a solution of freshly prepared $\mathrm{FeCl}_{3}(3.5 \mathrm{M})$ was added to content @1 mL/min keeping stirring to be continued over $24 \mathrm{~h}$. A dark brown precipitate was produced, that was subsequently filtered and successively washed with deionized water till the filtrate became free from chloride ions. Isolated PNCs was left for $6 \mathrm{~h}$ at room temperature and then dried at $40{ }^{\circ} \mathrm{C}$ at
$400 \mathrm{mmHg}$ for additional $8 \mathrm{~h}$. PIN was also prepared under similar reaction conditions in the absence of WC $[61,62]$.

\section{Preparation of electrodes}

Working electrodes (WE) were prepared through depositing PNCs over stainless steel plates of $1 \mathrm{~cm}^{2}$ area. Prior to deposition of PNCs, the plates were thoroughly finished with emery paper followed by ultrasonicated cleaning with acetone. A suspension of PNCs was prepared through ultrasonicating the composition of SPS $\left(7.5 \times 10^{-3} \mathrm{~g}\right)$ with graphite $\left(5.0 \times 10^{-3} \mathrm{~g}\right)$ and ammonium per sulfate $(80 \mu \mathrm{M})$ in the presence of PNCs in NMP $(1.5 \mathrm{~mL})$ over $2 \mathrm{~h}$. The suspension $(125 \mu \mathrm{L})$ was applied over electrode and left at room temperature for $8 \mathrm{~h}$, thereafter dried at $40^{\circ} \mathrm{C} / 400 \mathrm{~mm} \mathrm{Hg}$ for additional $48 \mathrm{~h}$ (Scheme 1). The electrodes with mass thickness ranging 1.80-46.15 $\left(\times 10^{-3} \mathrm{~g}\right)$ were obtained and employed for characterization [63].

\section{Instrumentations}

SEM images were recorded on JEOL, JSM $6610 \mathrm{LV}$ at 0.2 $\mathrm{KX}(7 \mu \mathrm{m})$ and $15 \mathrm{kV}$. For this purpose, the electrodes were prepared via mentioned procedure. The SEM images were scanned under identical conditions for comparable results. The conductivity data were recorded over Keithley fourpoint probe conductivity nanovoltmeter with current (6221 A) and voltage source $(2182 \mathrm{~V})$ in the range of 313-373 K.

The activation energy $\left(E_{\mathrm{a}}\right)$ was deduced through Arrhenius equation:

$\sigma=\sigma_{\mathrm{o}} \exp \left(-E_{\mathrm{a}} / k T\right)$,

where $\sigma$ is electrical electrodes conductivity, $\sigma_{0}$ is pre-exponential factor $k$ is Boltzmann constant and $T$ is absolute temperature [64].

FT-IR spectra were recorded on Thermo Nicolet ranging $4000-500 \mathrm{~cm}^{-1}$ in $\mathrm{KBr}$. XRD spectra were recorded over Rigaku-Geigerflex, X-Ray diffractometer using $\mathrm{Cu}-\mathrm{K} \alpha$ radiation $(\lambda=0.154 \mathrm{~nm})$ with $2 \theta$ ranging $10^{\circ}-90^{\circ}$ at $30 \mathrm{kV}$ and $15 \mathrm{~mA}$. Simultaneous TG-DTA-DTG was conducted over EXSTAR TG/DTA 6300 at sample weight $(\mathrm{mg})$ ranging $10.50-10.55$ at $10^{\circ} \mathrm{C} / \mathrm{min}$ in air.

The electrochemical studies of prepared electrodes were performed in PBS $(0.1 \mathrm{M})$ over IVIUM Potentiostat-Galvanostat using a triple-electrode cell assembly. WE were fabricated through depositing PNCs over SS plates. Pt foil $\left(1 \mathrm{~cm}^{2}\right)$ and $\mathrm{Ag} / \mathrm{AgCl}$ were used as auxiliary and reference electrodes. All peak currents $(\mu \mathrm{A})$ and peak potentials (V) were expressed in due units. Calibration curves were obtained from SWV by plotting maximum peak current and respective increasing concentration of CHL.

Limit of detection (LOD) and limit of quantification (LOQ) were calculated from calibration curve using formula: 
Scheme 1 Preparation of electroactive material and modification of electrode using PNCs for CHL sensing

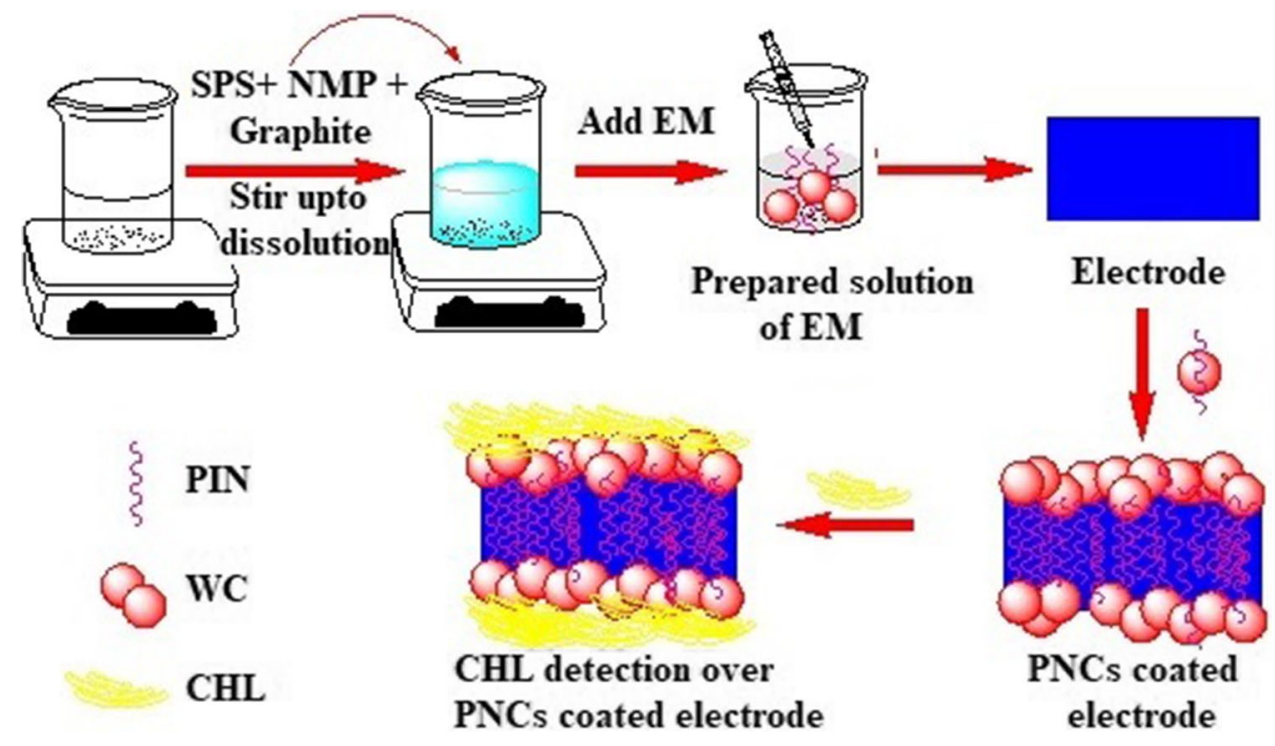

$\mathrm{LOQ}=10 \mathrm{~s} / \mathrm{m}$ and $\mathrm{LOD}=3.3 \mathrm{~s} / \mathrm{m}$, where $\mathrm{s}$ is intercept and $\mathrm{m}$ is slope of the calibration curve. Stability of electrodes was investigated through electrochemical impedance spectra (EIS) and circuit simulation was conducted using Randles diagrams.

\section{Results and discussion}

\section{Spectral analysis}

PIN shows characteristic wave numbers $\left(\mathrm{cm}^{-1}\right)$ corresponding to $v \mathrm{~N}-\mathrm{H}(3138.00), v \mathrm{C}-\mathrm{H}(2925.39), \nu \delta \mathrm{O}-\mathrm{H}(1617.78)$ $\nu \mathrm{C}-\mathrm{C}(1454.64)$ and $\delta \mathrm{Ar}-\mathrm{H}$ (745.48). The wave numbers at 2925.39 and 2852.80 attribute to interaction of CTAB with

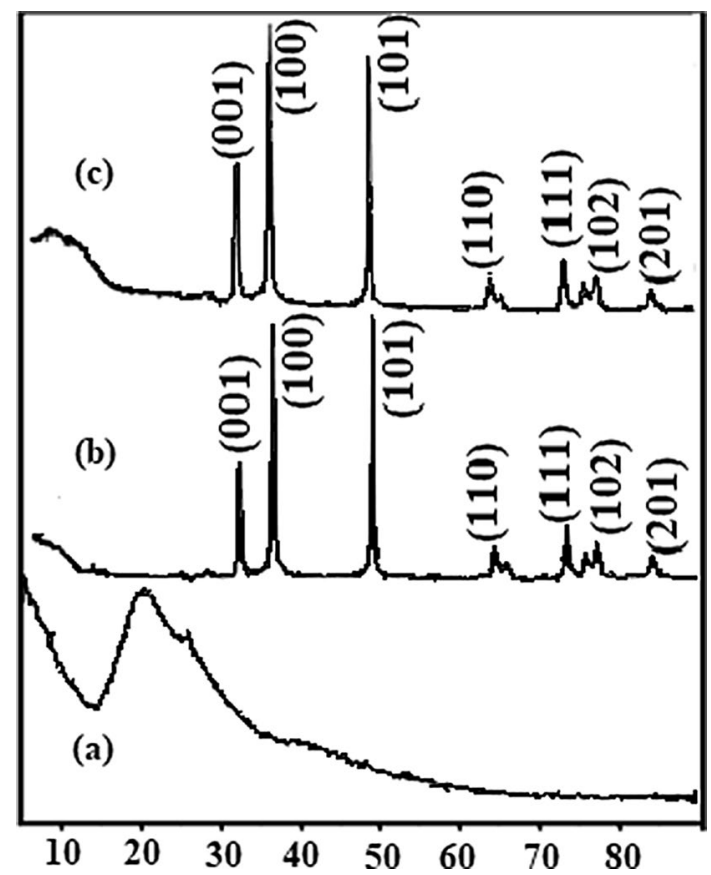

Fig. 2 XRD spectra of a PIN, b WC and $\mathbf{c}[\mathrm{II}]$

PIN. The wave number at $1110.96,1334.07$ and 1568.39 $\mathrm{cm}^{-1}$ correspond to $\nu \mathrm{C}-\mathrm{N}, \nu \mathrm{C}=\mathrm{N}$ and $\delta \mathrm{N}-\mathrm{H}$ deformation [65].

WC has shown by the low-frequency fingerprint region at $665.82 \mathrm{~cm}^{-1}$ [66].

[III] shows all the characteristic absorption bands of PIN. EM shows absorptions corresponding to $v \mathrm{~N}-\mathrm{H}$ (3137.12), $v \mathrm{C}-\mathrm{H}$ (3017.8) and symmetric stretches of WC near the low-frequency fingerprint region (655.84) and out-of-plane 

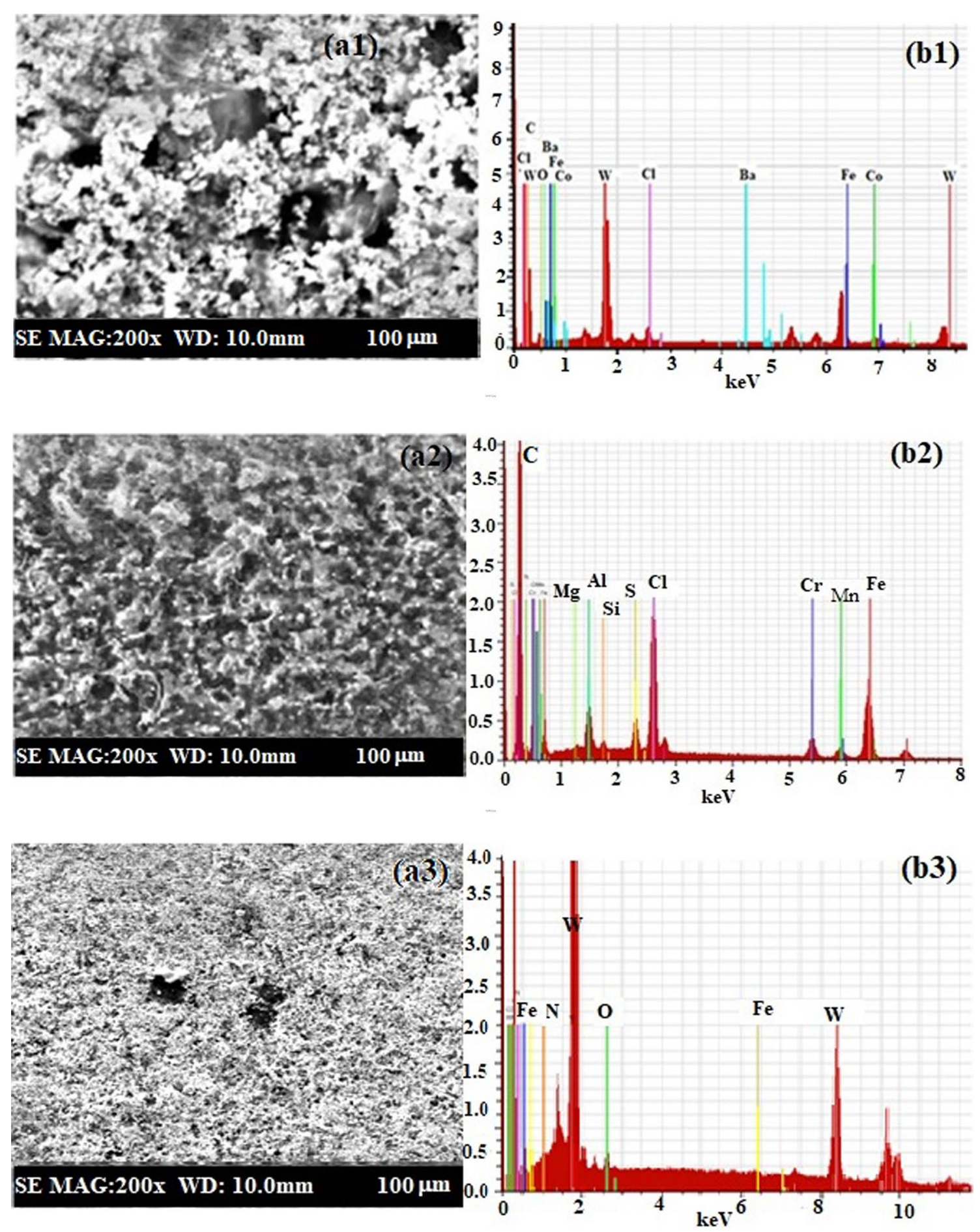

Fig. 3 SEM-EDX of electrodes coated with WC $\left(\mathbf{a}_{1}, \mathbf{b}_{1}\right), \operatorname{PIN}\left(\mathbf{a}_{2}, \mathbf{b}_{2}\right)$ and PIN/WC $\left(\mathbf{a}_{3}, \mathbf{b}_{3}\right)$

deformation for $\mathrm{C}-\mathrm{H}$ (746.58) (Fig. 1). Interaction of WC has shifted the wave number of PIN to lower values.
XRD

The XRD spectra of the PIN, WC and [III] are shown in Fig. 2. Broad peak at $20.35^{\circ}$ attributes to amorphous nature of PIN. Debye-Scherrer calculations provided the corresponding crystallite size of nanoparticles ranging 
10-22 nm [67]. Diffraction peaks at $31.68^{\circ}(2.82), 35.71^{\circ}$ (2.51), $48.38^{\circ}(1.88), 64.05^{\circ}(1.45), 65.76^{\circ}(1.42), 73.37^{\circ}$ $(1.29), 75.63^{\circ}(1.25), 77.26^{\circ}(1.23), 84.26^{\circ}(1.15)$ correspond to [001], [100], [101], [110], [002], [111], [200], [102], [201] planes of WC. The planes of hexagonal were well matched with JCPDS 73-0471 [68]. Diffraction peaks at $31.03^{\circ}(2.95), 35.31^{\circ}(2.54), 47.88^{\circ}(1.89), 63.65^{\circ}$ (1.46), $72.96^{\circ}(1.29), 75.15^{\circ}(1.26), 76.87^{\circ}(1.23), 83.81^{\circ}$ (1.15) corresponding to [001], [100], [101], [110], [111], [200], [102], [201] planes reveal the presence of WC in PIN matrix.

\section{Surface morphology of electrodes}

Morphology of fabricated electrodes along with quantitative elemental composition was analyzed through SEM-EDX study. To compare the morphology, all electrodes were imaged under identical conditions at $1 \mathrm{KX}, 10 \mu \mathrm{M}$ and camera width of $10 \pm 1 \mathrm{~nm}$. EDX spectrum shows the presence of $\mathrm{W}$ and high $\mathrm{C}$ content in the EM as well as quantity of other elements. EDX represents qualitative detection of elements present in EM. To simulate the emission of X-rays, high-energy beam of charged particles was focused on to the EM. The difference between energies of higher and lower energy shell is released in the form of X-rays which is measured by spectrometer.

SEM and EDX of WC, PIN and PNCs are sequentially shown in Fig. 3a1-a3 and b1-b3, respectively. The dark and bright phases in SEM images represent the morphology of PIN and WC, respectively. Electrodes derived from PIN show a co-continuous morphology without any distinct phase separation. SEM of PIN-coated electrode showed granular structure with rough morphology, which concludes that the nature of particles formed was irregular. Blending of PIN with WC, has afforded with rough morphology. It is observed from SEM images that intercalation of WC into PIN matrix also increases, which leads to roughness in electrode surface. The synergy between the constituents may be weak or strong, which is regulated by the technique used for synthesis of the composite [69]. The reason of surface roughness may be due to the non-homogenized distribution of WC into polymer phase during the procedure of electrode preparation. The morphological structure of PNCs is found to be different from PIN and reveals homogeneous dispersion of WC nanoparticles into PIN matrix.

\section{Thermal stability}

Information regarding thermal stability of PIN as well as [III] is provided by thermal studies (Fig. 4). The weight loss caused by evaporation of physically adsorbed moisture and residual solvents is observed in the curves at a temperature lower than $200{ }^{\circ} \mathrm{C}$. The weight residue (Wr) corresponding
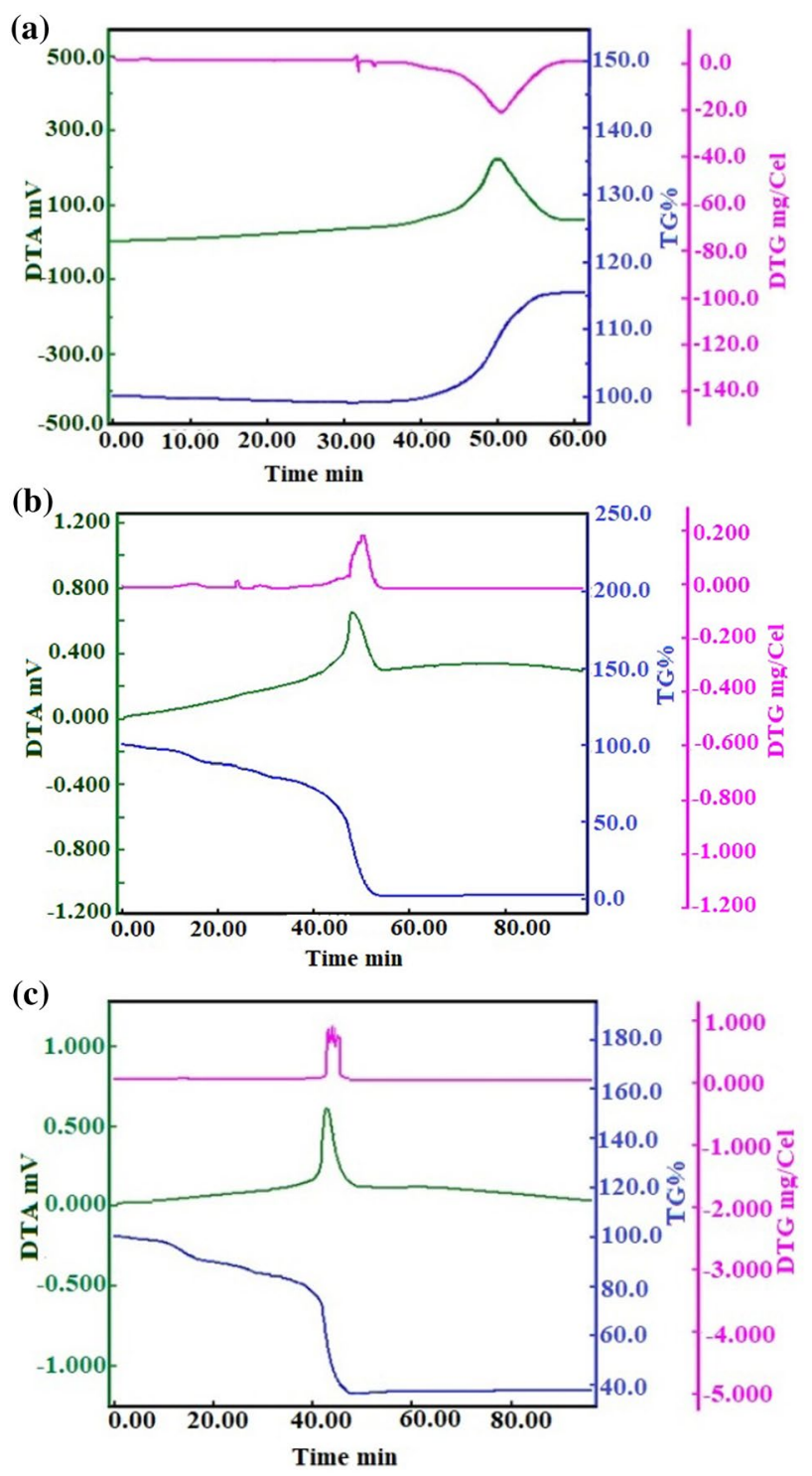

Fig. 4 a TG-DTA-DTG of WC, b TG-DTA-DTG of PIN, c TGDTA-DTG of III

to TG is expressed as \%w/w. DTA signals and rate of degradation of samples in DTG are expressed as $\mathrm{mV}$ and $\mathrm{mg} /$ Cel, respectively. The heat of fusion data revealed through DTA has been expressed in $\mathrm{mJ} / \mathrm{mg}$. TG onset shows thermal stability of WC up to $384{ }^{\circ} \mathrm{C}$. WC shows weight gain of $104.90 \%$ due to oxidation at $528{ }^{\circ} \mathrm{C}$ [22]. Decomposition of WC was progressed at the rate of $-21.97 \times 10^{-3} \mathrm{mg} /{ }^{\circ} \mathrm{C}$ at $552{ }^{\circ} \mathrm{C}$ with DTA signal $(0.22 \mathrm{mV})$ at $548^{\circ} \mathrm{C}$ Decomposition of WC was concluded at $597^{\circ} \mathrm{C}$ leaving char residue of $114.70 \mathrm{wt} \%$ (Fig. 4a).

PIN was decomposed with TG onset at $337{ }^{\circ} \mathrm{C}$ leaving 79.4\% Wr. Decomposition of PIN was progressed at the rate of $197.6 \times 10^{-3} \mathrm{mg} /{ }^{\circ} \mathrm{C}$ at $559^{\circ} \mathrm{C}$ with DTA signal $(0.65 \mathrm{mV})$ at $543{ }^{\circ} \mathrm{C}$. Decomposition of PIN was concluded at $573{ }^{\circ} \mathrm{C}$ 

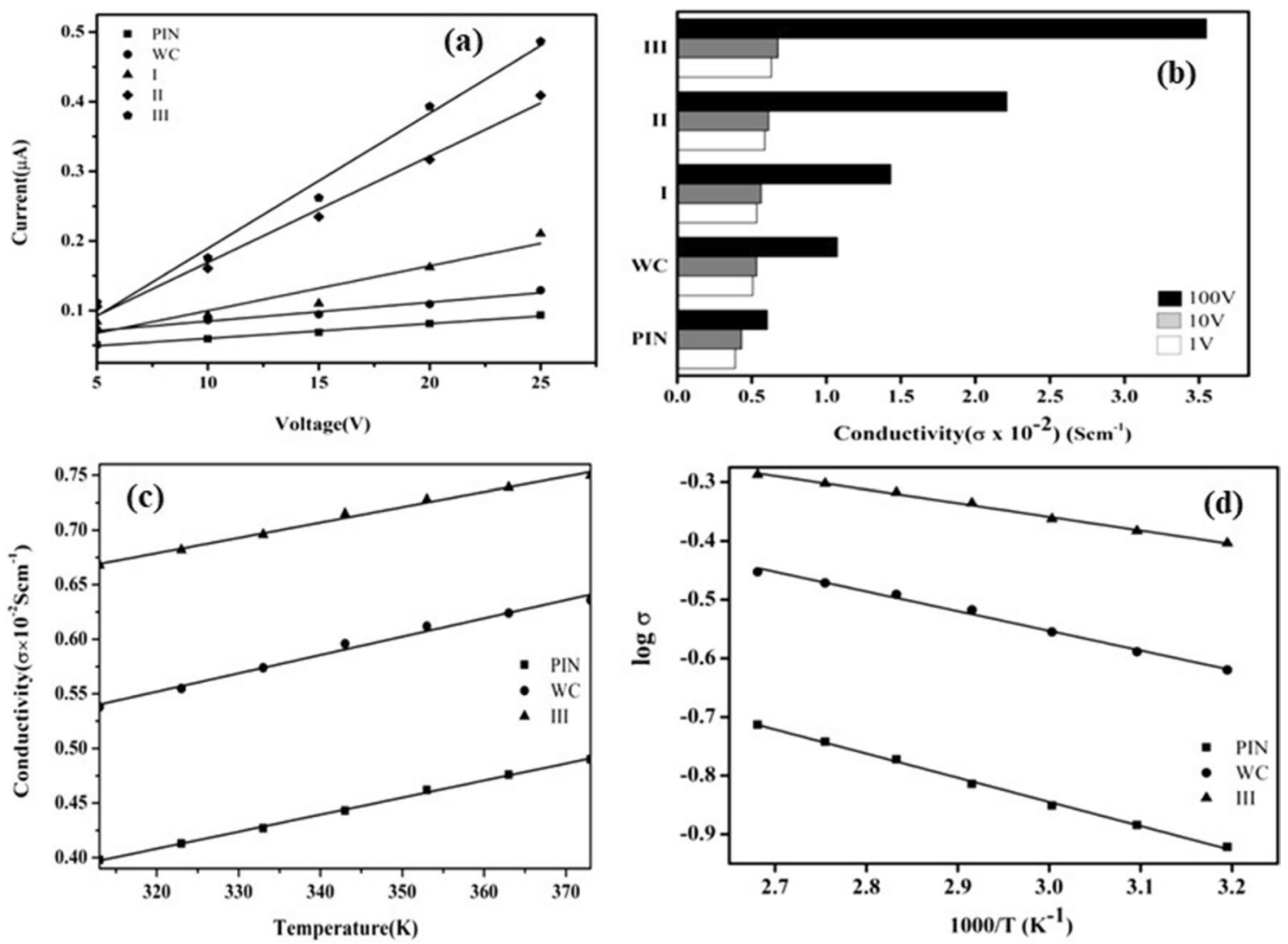

Fig. 5 a $\sigma$ DC of electrodes, $\mathbf{b}$ effect of voltage on $\sigma$ DC of electrodes, $\mathbf{c}$ effect of temperature on the conductivity of electrodes. $\mathbf{d}$ Arrhenius plots of electrodes

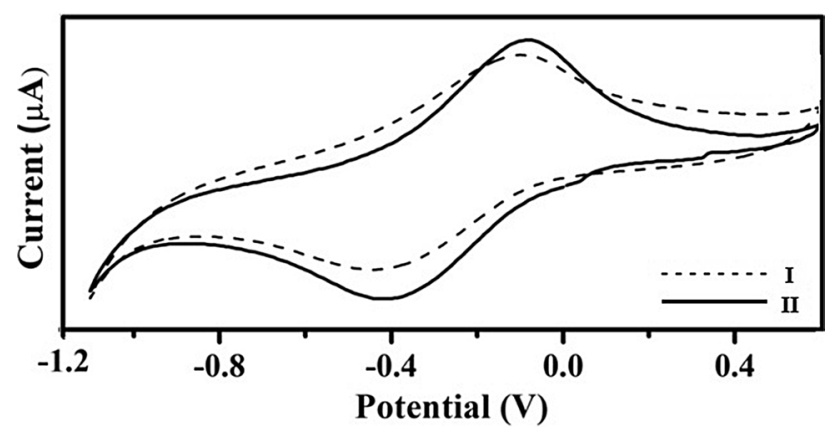

Fig. 6 Comparison of CV curves of [I] and [II] electrode

leaving char residue of $1.90 \mathrm{wt} \%$. DTA reveals fusion of PIN with $\Delta H_{\mathrm{f}}$ of $-10.6 \times 10^{3} \mathrm{~mJ} / \mathrm{mg}$ (Fig. 4b). [III] shows single-step decomposition with TG onset at $328{ }^{\circ} \mathrm{C}$ leaving $85 \% \mathrm{Wr}$. The collective weight loss of $15.0 \%$ wt indicates that due to filling of WC, the thermal stability of PIN was compromised. Decomposition of [III] was progressed at the rate of $0.858 \mathrm{mg} /{ }^{\circ} \mathrm{C}$ at $519{ }^{\circ} \mathrm{C}$ with DTA signal $(0.61 \mathrm{mV})$ at $520{ }^{\circ} \mathrm{C}$. TG endset of [III] was appeared at $538^{\circ} \mathrm{C}$ leaving $36.2 \%$ char residue. DTA reveals fusion of [III] with
$\Delta H_{\mathrm{f}}$ of $-7.44 \times 10^{3} \mathrm{~mJ} / \mathrm{mg}$ (Fig. $4 \mathrm{c}$ ). Thermal data reveal that due to addition of WC, the thermal stability of [III] was compromised.

\section{Electrical conductivity}

The linear variation in $\mathrm{I}-\mathrm{V}$ (Fig. 5a) at room temperature implies the ohmic conduction behaviour of WC in PIN [70]. The increased conductivity attributes to high conductivity of WC as well as interaction between PIN and WC which favored charge transfer process [71]. Effect of WC on $\sigma D C$ of electrodes was studied under various voltages ranging $1-100 \mathrm{~V}$ at room temperature (Fig. 5b). It was found that the conductivity of the [III] increased with concentration of $\mathrm{WC}$ and maximum for $100 \mathrm{~V}$ which is $3.54 \times 10^{-2} \mathrm{Scm}^{-1}$. The $\sigma \mathrm{DC}$ measurements were also performed at temperature range 313-373 K (Fig. 5c). It was observed that increasing value of $\sigma \mathrm{DC}$ with temperature defines the semiconducting behaviour of PNCs and maximum $\sigma \mathrm{DC}$ was observed for [III]. Increase in $\sigma \mathrm{DC}$ with temperature attributes to enhanced charge mobility across PNCs. Using theoretical Arrhenius model, the calculated activation energies for 
Fig. 7 Mechanism of electrochemical reaction of the binary composite indicating electron transfer

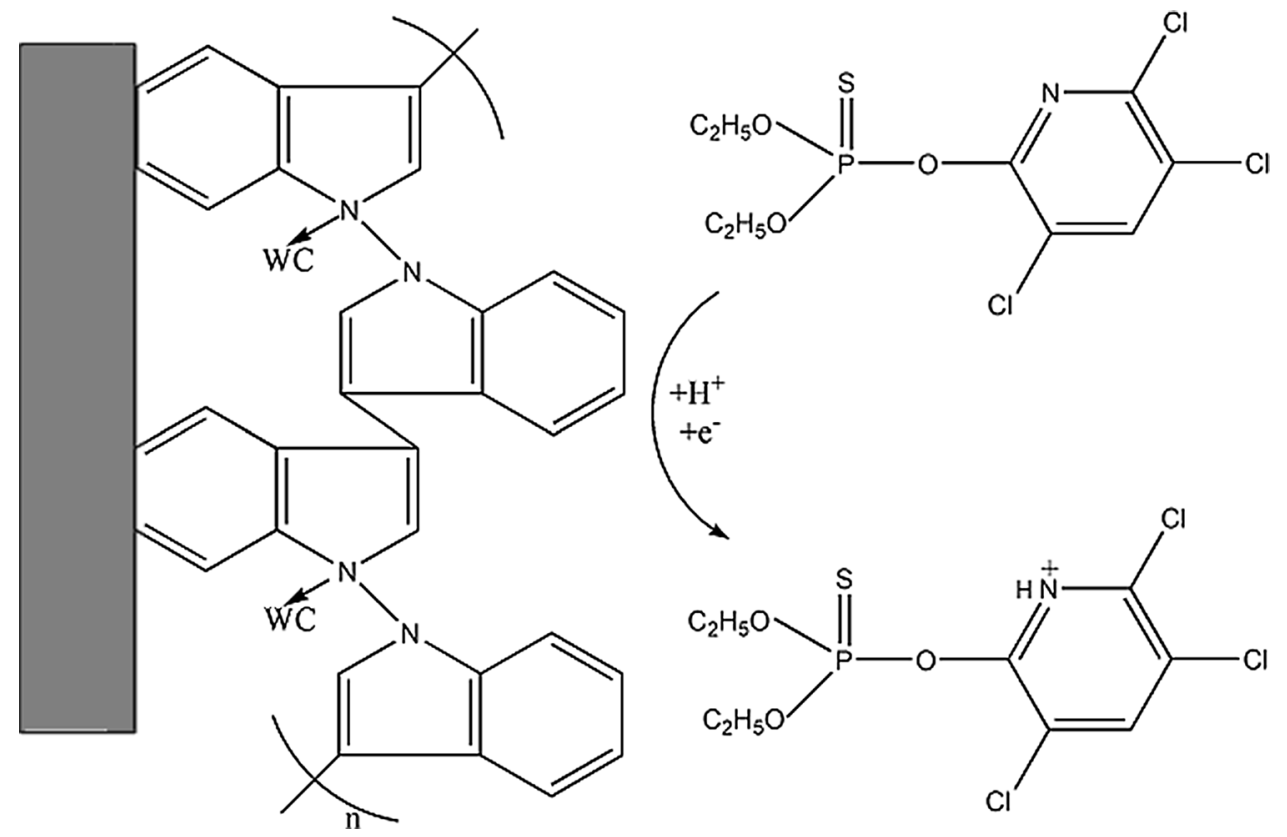

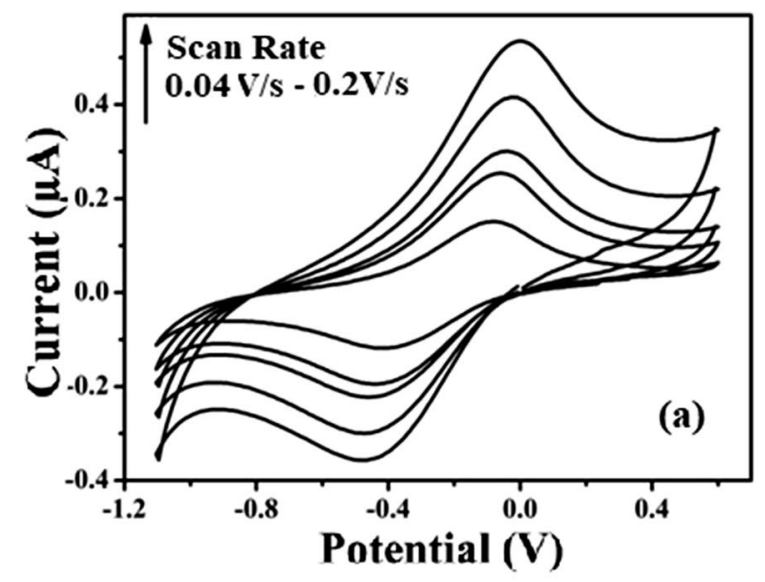
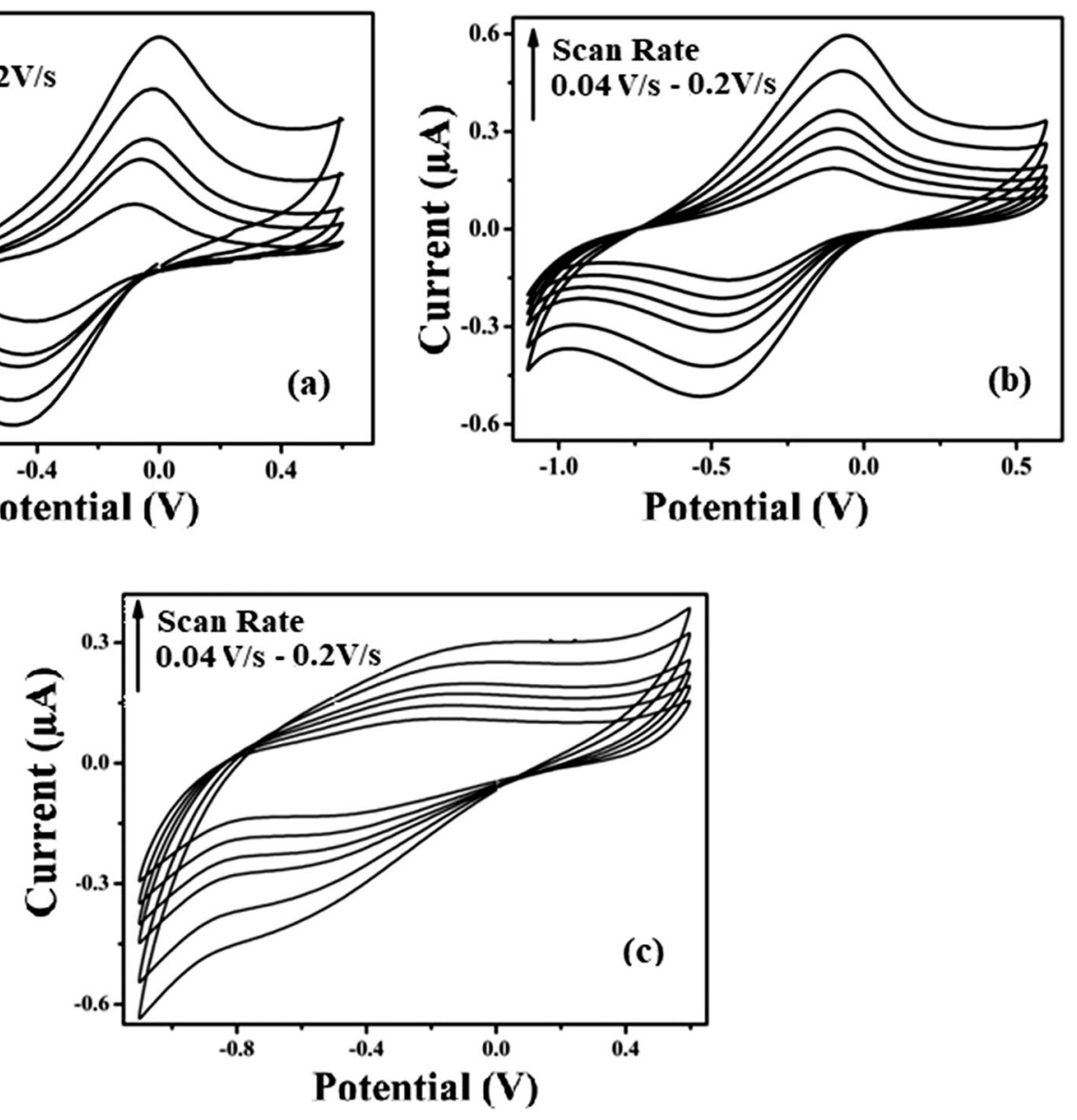

Fig. 8 a CV of [I] vs. $\mathrm{Ag} / \mathrm{Ag}^{+}$electrode recorded in $0.1 \mathrm{M}$ PBS (pH 7.4) at scan rates $0.04,0.06,0.08,1.0,1.5$ and $2.0 \mathrm{mV} / \mathrm{s}$. b CV of [II] composite fabricated SSPE recorded in 0.01 M PBS ( $\mathrm{pH}$ 7.4) at scan rates $0.04,0.06,0.08,1.0,1.5$ and $2.0 \mathrm{mV} / \mathrm{s}$. c [III] composite fabricated electrode 


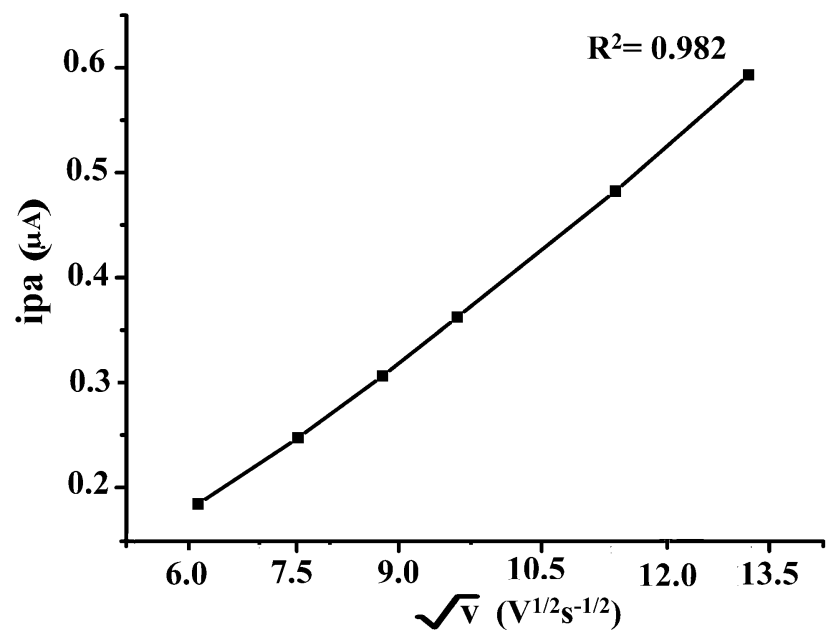

Fig. 9 Linear regression curve between anodic peak current and root of scan rate

PIN, WC and [III] were found as $0.035,0.028$ and $0.019 \mathrm{eV}$ (Fig. 5d).

\section{EC behavior of modified electrode}

\section{Cyclic voltammetry}

$\mathrm{CV}$ is the most popular continuous wave technique employed to investigate the redox behavior and electron transfer kinetics of molecules over electrochemically active surface. $\mathrm{CV}$ presents the set of anodic $\left(E_{\mathrm{pa}}\right)$ and cathodic peak $\left(E_{\mathrm{pc}}\right)$ potentials along with respective anodic $\left(i_{\mathrm{pa}}\right)$ and cathodic $\left(i_{\mathrm{pc}}\right)$ peak currents. Potential applied across WE moves back and forth past the formal potential. This leads to current flow across the electrode that renders the redox behavior of analyte [72, 73].

Redox behavior was investigated through scanning the $\mathrm{CV}$ of CHL in PBS (0.1 M, pH 7.4)@ $40 \mathrm{mV} \mathrm{s}^{-1}$ over WE derived from PNCs [I] and [II] (Fig. 6). Voltammograms were recorded till fivefold degeneracy in potential window of -0.11 to +0.55 . [I] has rendered a well-defined redox behavior with peaks peak potentials $(-\mathrm{V})$ ranging 0.089-0.418 V. Under identical conditions, [II] has shown the peak potentials $(-\mathrm{V})$ of $0.093 \mathrm{~V}$ and 0.43 . Increase in peak current attributes to the formation of electron-conducting tunnel during redox reaction of CHL over [II]. The electron transfer mechanism during redox behavior $\mathrm{f} \mathrm{CHL}$ over [II] has been presented in Fig. 7. Based on peak potential deuced from $\mathrm{CV}$ of [II], the redox behavior of CHL over electrodes was found to lead according to one electron transfer mechanism between electrode surface and CHL generating synergy on EC properties [74].
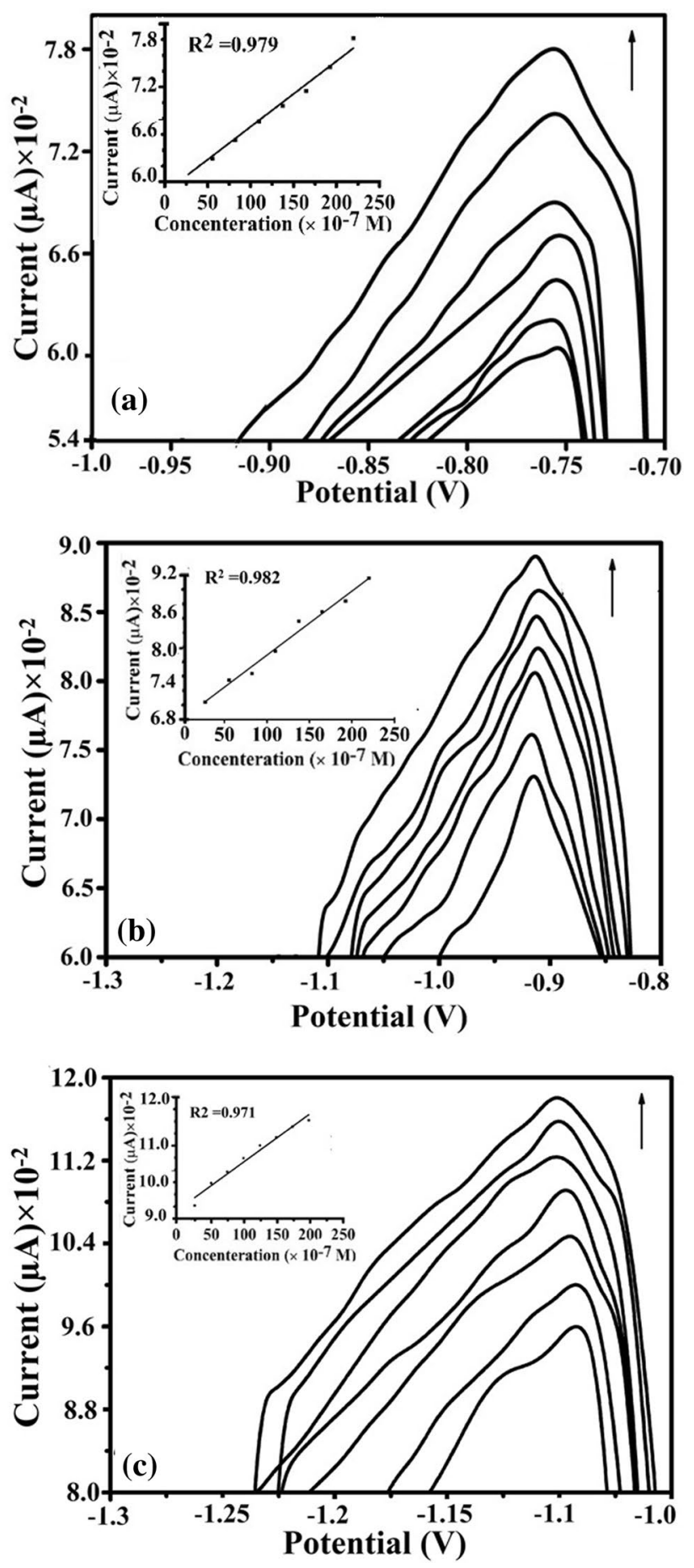

Fig. 10 SWV curves and calibration plot of $\mathbf{a}[\mathrm{I}], \mathbf{b}$ [II] and $\mathbf{c}[\mathrm{III}]$ against increasing CHL amount in $\mathrm{pH} 7.4$ of PBS

\section{Effect of scan rate on CV}

Frequent elevation in scan rate has raised the Ipa $(\mu \mathrm{A})$ of $[\mathrm{I}]$ from 0.084 to 0.279 (Fig. 8a). The coinciding anodic peak potential was observed ranging from -0.089 to $-0.013 \mathrm{~V}$. At the same time, there was reduction in Ipc $(-\mu \mathrm{A})$ 


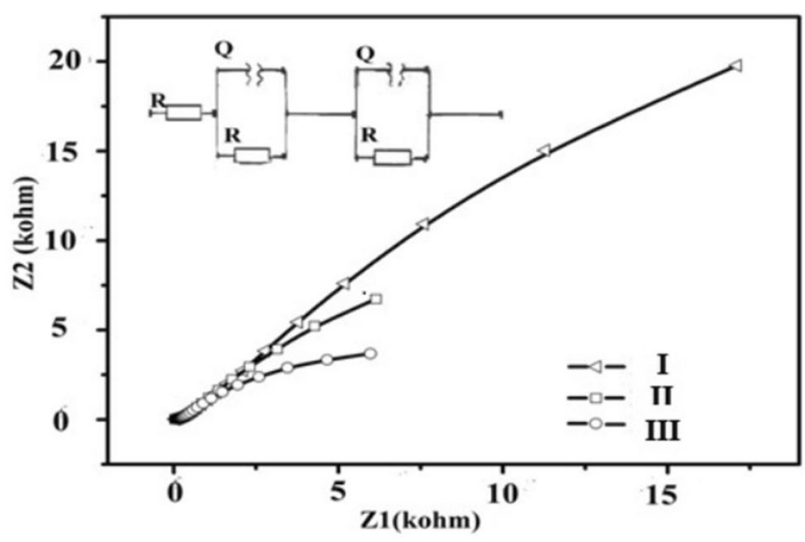

Fig. 11 Electrochemical impedance spectra of [I], [II] and [III] electrodes

ranging 0.079-0.235 with corresponding Epc $(-\mathrm{V})$ ranging $0.418-0.454$. For [II] with increase in scan rate $\left(\mathrm{Vs}^{-1}\right)$ from 0.04 to 0.2 , there was subsequent increase in $I_{\mathrm{pa}}, E_{\mathrm{pa}}, I_{\mathrm{pc}}$ and $E_{\mathrm{pc}}$ ranging $0.111-0.329,-0.093$ to $-0.065 \mathrm{~V},-0.099$ to -0.325 and -0.43 to -0.52 , respectively (Fig. $8 b$ ). However, no redox behavior was shown by [III] irrespective of scan rate (Fig. 8c). Figure 9 shows linear regression curve for [II] between Ipa and square root of scan rate. A comparative account reveals higher electrochemical behavior of [II] over [I].

\section{Square wave voltammetry}

The SWV experiments have been performed in the potential window (V) from -2.0 to 2.0 at pulse amplitude $2 \mathrm{mV}$, scan increment $20 \mathrm{mV}$ and frequency $25 \mathrm{~Hz}$. A comparative SWV voltammograms of electrodes in 0.1 M PBS (pH 7.4) at varying concentrations of CHL are sketched in Fig. 10a-c. The presence of WC in the PIN matrix has raised the peak current that attributes to increase in the sensitivity towards PNCs. With concentration of CHL, the peak was increased over [I] from 6.204 to 7.808 (Fig. 10a). Under identical conditions, the peak currents of [II] and [II] were raised in the range of 7.699-8.99 and 9.892-11.90 (Fig. 10b, c). Linear range of proposed CHL sensor was found to be $25 \times 10^{-7}$ to $225 \times 10^{-7} \mathrm{~mol} \mathrm{~L}^{-1}$ and calibration curves obtained between maximum peak current and concentration of $\mathrm{CHL}$ added in SWV were used to calculate LOD and limit of quantification LOQ.

The proposed sensor demonstrates acceptable quantification of CHL with significantly low LOD values. The calibration plots for quantification of CHL at [I], [II] and [III] was obtained by studying the effect of increase in CHL concentration on peak current. The LOD obtained for [I], [II] and [III] are $4.8 \times 10^{-8} \mathrm{~mol} \mathrm{~L}^{-1}, 5.94 \times 10^{-8} \mathrm{~mol} \mathrm{~L}^{-1}$ and $4.49 \times 10^{-8} \mathrm{~mol} \mathrm{~L}^{-1}$. LOQ for [I], [II] and [III] are $14.5 \times 10^{-8} \mathrm{~mol} \mathrm{~L}^{-1}, 18 \times 10^{-8} \mathrm{~mol} \mathrm{~L}^{-1}$ and $13.6 \times 10^{-8}$ mol L ${ }^{-1}$, respectively. The correlations between the concentration and peak current were in linear relation with correlation coefficient $(r)$ for [I], [II] and [III] was 0.979 , $0.982,0.971$, respectively, indicating good correlation.

\section{Electrochemical impedance spectroscopy}

The impedance data have been expressed in $\mathrm{Hz}$ and spectrum was examined by equivalent electrical circuit model (Fig. 11). The elements of the circuit are general electrical components, which include polarization resistance or charge transfer, solution resistance and a double-layer capacitor. EIS measurements were managed by FRA. Nyquist plots at higher and lower frequency range appeared as semicircle attributing to electron transfer resistance (Ret). High impedance in the form of semicircular loop was observed at the surface of electrodes covered with coating of PNCs; whereas, loops were opened within $24 \mathrm{~h}$ representing the destruction of coating.

For $I, R_{\mathrm{p}}$ was $8.506 \times 10^{2}$ and $|Z|$ appeared at $1.200 \times 10^{3}$. For $[\mathrm{II}], R_{\mathrm{p}}$ was $4.973 \times 10^{2}$ and $\mathrm{IZI}$ appeared at $6.396 \times 10^{2}$. [III] has shown $R_{\mathrm{p}}$ of $2.669 \times 10^{2}$ and $\mid \mathrm{ZI}$ appeared at $2.998 \times 10^{2}$. With the fabrication of electrode with PNCs, the diameter of semicircle decreased, which shows that PNCs possess high electrical conductivity with low charge transfer resistance. It is observed from
Fig. 12 SEM images of II electrode a At $1.0 \mathrm{KX}$, b At $2.7 \mathrm{KX}$
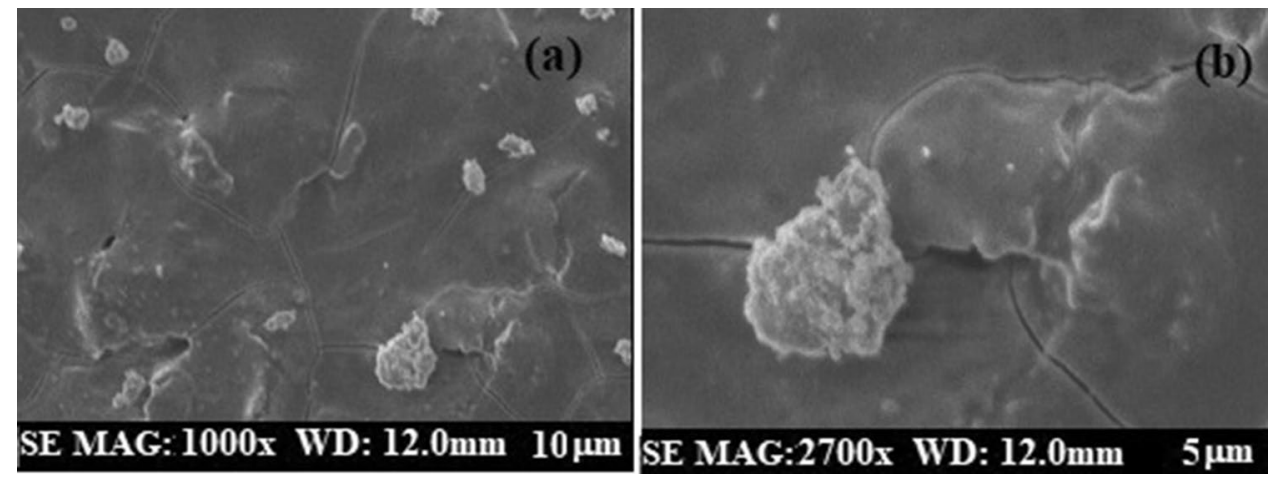
Fig. 11 that the diameter of the semicircles was successively decreased in the order from [I] to [III], that indicates successive increase in electron transfer at the surface of PNCs-coated electrode. Best semicircular loop in [III] represents highest charge storage and capacitive behavior of [III]. In case of EIS studies [II], opening of semicircular loop indicates the diffusion of electrolyte and that is also responsible for cracking of electrode surface as shown in SEM images (Fig. 12a, b).

\section{Conclusion}

A series of electrochemical polymer nanocomposite (PNC)based electrode was developed by an easy and effective chemical oxidative polymerization method using various concentrations of WC ranging $0-30 \mathrm{wt} \%$. Electrodes from PNCs were developed over SS plates and used for electrochemical quantification of chlorpyrifos (CHL) in phosphate buffer (PBS, 0.1 M) at 7.4. Electroanalytical methods based on square wave voltammetry (SWV) and electrochemical impedance spectroscopy (EIS) reveal immense feasibility of electrodes towards quantification of CHL with stability in PBS. The electrical and electrochemical behavior of electrodes was found synergistic with concentration of WC in PIN. DC conductivity of electrodes was found in increasing order with concentration of WC. Electrodes with $5 \mathrm{wt} \%$ of WC have shown enhanced redox behavior of CHL with limits of detection and quantification $\left(10^{-8} \mathrm{~mol} \mathrm{~L}^{-1}\right)$ up to 5.94 and 18. Study reveals that incorporation of WC in PIN provides a novel nanohybrid electrode coating material for efficient detection of CHL.

Acknowledgements Financial support by the Ministry of Defence No. ERIP/ER/0703649/M/01 is hereby acknowledged.

\section{Compliance with ethical standards}

Conflict of interest No potential conflict of interest was reported by the author.

Open Access This article is licensed under a Creative Commons Attribution 4.0 International License, which permits use, sharing, adaptation, distribution and reproduction in any medium or format, as long as you give appropriate credit to the original author(s) and the source, provide a link to the Creative Commons licence, and indicate if changes were made. The images or other third party material in this article are included in the article's Creative Commons licence, unless indicated otherwise in a credit line to the material. If material is not included in the article's Creative Commons licence and your intended use is not permitted by statutory regulation or exceeds the permitted use, you will need to obtain permission directly from the copyright holder. To view a copy of this licence, visit http://creativecommons.org/licenses/by/4.0/.

\section{References}

1. Kaur, N., Prabhakar, N.: Current scenario in organophosphates detection using electrochemical biosensors. Trends Anal. Chem. 92, 62-85 (2017)

2. Ensafi, A.A., Rezaloo, F., Rezaei, B.: Electrochemical determination of fenitrothion organophosphorus pesticide using polyzincon modified-glassy carbon electrode. Electroanal. 29(12), 2839-2846 (2017)

3. Mehta, J., Vinayak, P., Tuteja, S.K., Chhabra, V.A., Bhardwaj, N., Paul, A.K., Deep, A.: Graphene modified screen printed immunosensor for highly sensitive detection of parathion. Biosens. Bioelectron. 83, 339-346 (2016)

4. Singh, M., Kashyap, H., Singh, P.K., Mahata, S., Rai, V.K., Rai, A.: AuNPs/Neutral red-biofunctionalized graphene nanocomposite for nonenzymatic electrochemical detection of organophosphate via $\mathrm{NO}_{2}$ reduction. Sensor Actuat. B. 290, 195-202 (2019)

5. Pearson, J.N., Patel, M.: The role of oxidative stress in organophosphate and nerve agent toxicity. Ann. N. Y. Acad. Sci. 1378(1), 17 (2016)

6. Berijani, S., Assadi, Y., Anbia, M., Hosseini, M. R. M., Aghaee, E.: Dispersive liquid-liquid microextraction combined with gas chromatography-flame photometric detection: very simple, rapid and sensitive method for the determination of organophosphorus pesticides in water. J. Chrom. A. 1123(1), 1-9 (2006)

7. Saunders, M., Magnanti, B.L., Carreira, S.C., Yang, A., AlamoHernández, U., Riojas-Rodriguez, H., Bartonova, A.: Chlorpyrifos and neurodevelopmental effects: a literature review and expert elicitation on research and policy. Environ. Health. 11(1), S5 (2012)

8. Guardino, X., Obiols, J., Rosell, M.G., Farran, A., Serra, C.: Determination of chlorpyrifos in air, leaves and soil from a greenhouse by gas-chromatography with nitrogen-phosphorus detection, high-performance liquid chromatography and capillary electrophoresis. J. Chrom. A 823(1-2), 91-96 (1998)

9. Duffy, G.F., Moore, E.J.: Electrochemical immunosensors for food analysis: a review of recent developments. Anal. Lett. 50(1), 1-32 (2017)

10. Yang, G., Chen, X., Pan, Q., Liu, W., Zhao, F.: A novel photoelectrochemical sensor for thiamphenicol based on porous three-dimensional imprinted film. Int. J. Electrochem. Sci. 12(8), 7272-7286 (2017)

11. Zamfir, L.G., Rotariu, L., Bala, C.: Acetylcholinesterase biosensor for drugs based on tetrathiafulvalene-tetracyanoquinodimethane/ionic liquid conductive gels. Biosens. Bioelectron. 46, 61-67 (2013)

12. Chauhan, N., Narang, J., Pundir, C.S.: Immobilization of rat brain acetylcholinesterase on porous gold-nanoparticle- $\mathrm{CaCO}_{3}$ hybrid material modified Au electrode for detection of organophosphorous insecticides. Int. J. Biol. Macromol. 49(5), 923-929 (2011)

13. Rackus, D.G., Shamsi, M.H., Wheeler, A.R.: Electrochemistry, biosensors and microfluidics: a convergence of fields. Chem. Soc. Rev. 44(15), 5320-5340 (2015)

14. Yola, M.L., Atar, N.: A highly efficient nanomaterial with molecular imprinting polymer: carbon nitride nanotubes decorated with graphene quantum dots for sensitive electrochemical determination of chlorpyrifos. J. Electrochem. Soc. 164(6), B223-B229 (2017)

15. Ramasubramanian, T., Paramasivam, M.: Development and validation of a multiresidue method for the simultaneous determination of organophosphorus insecticides and their toxic metabolites in sugarcane juice and refined sugar by gas chromatography with flame photometric detection. J. Sep. Sci. 39(11), 2164-2171 (2016) 
16. Shamili, A., Dadfarnia, S., Shabani, A.M.H., Saeidi, M., Moghadam, M.R.: High performance liquid chromatographic determination of diazinon after its magnetic dispersive solid-phase microextraction using magnetic molecularly imprinted polymer. Food Anal. Method. 9, 2621-2630 (2016)

17. Sreedhar, N.Y., Kumar, M.S., Krishnaveni, K.: Sensitive determination of chlorpyrifos using $\mathrm{Ag} / \mathrm{Cu}$ alloy nanoparticles and graphene composite paste electrode. Sens. Act. B: Chem. 210, 475-482 (2015)

18. Vera, R., Insa, S., Fontas, C., Antico, E.: A new extraction phase based on a polymer inclusion membrane for the detection of chlorpyrifos, diazinon and cyprodinil in natural water samples. Talanta 185, 291-298 (2018)

19. Pedrosa, V.D.A., Codognoto, L., Avaca, L.A.: Electroanalytical determination of 4-nitrophenol by square wave voltammetry on diamond electrodes. J. Braz. Chem. Soc. 14(4), 530-535 (2003)

20. Bebeselea, A., Manea, F., Burtica, G., Nagy, L., Nagy, G.: Electrochemical degradation and determination of 4-nitrophenol using multiple pulsed amperometry at graphite based electrodes. Chem. Bull. Politech. Univ. Timisoara. 53(67), 1-2 (2008)

21. Viswanathan, S., Radecka, H., Radecki, J.: Electrochemical biosensor for pesticides based on acetylcholinesterase immobilized on polyaniline deposited on vertically assembled carbon nanotubes wrapped with ssDNA. Biosens. Bioelectron. 24(9), 27722777 (2009)

22. Liu, K., Dong, H., Deng, Y.: Recent advances on rapid detection of pesticides based on enzyme biosensor of nanomaterials. J. Nanosci. Nanotech. 16(7), 6648-6656 (2016)

23. Manisankar, P., Viswanathan, S., Pusphalatha, A.M., Rani, C.: Electrochemical studies and square wave stripping voltammetry of five common pesticides on poly 3, 4-ethylenedioxythiophene modified wall-jet electrode. Anal. Chim. Acta 528(2), 157-163 (2005)

24. Kaur, B., Srivastava, R.A.: Polyaniline-zeolite nanocomposite material based acetylcholinesterase biosensor for the sensitive detection of acetylcholine and organophosphates. New J. Chem. 39(9), 6899-6906 (2015)

25. Du, D., Liu, J., Zhang, X., Cui, X., Lin, Y.: One-step electrochemical deposition of a graphene- $\mathrm{ZrO}_{2}$ nanocomposite: preparation, characterization and application for detection of organophosphorus agents. J. Mat. Chem. 21(22), 8032-8037 (2011)

26. Gong, J., Miao, X., Zhou, T., Zhang, L.: An enzymeless organophosphate pesticide sensor using Au nanoparticle-decorated graphene hybrid nanosheet as solid-phase extraction. Talanta 85(3), 1344-1349 (2011)

27. Zhu, W., Liu, W., Li, T., Yue, X., Liu, T., Zhang, W., Wang, J.: Facile green synthesis of graphene-Au nanorod nanoassembly for on-line extraction and sensitive stripping analysis of methyl parathion. Electrochim. Acta 146, 419-428 (2014)

28. Ebrahim, S., El-Raey, R., Hefnawy, A., Ibrahim, H., Soliman, M., Abdel-Fattah, T.M.: Electrochemical sensor based on polyaniline nanofibers/single wall carbon nanotubes composite for detection of malathion. Synth. Met. 190, 13-19 (2014)

29. Prabhakar, N., Thakur, H., Bharti, A., Kaur, N.: Chitosan-iron oxide nanocomposite based electrochemical aptasensor for determination of malathion. Anal. Chim. Acta 939, 108-116 (2016)

30. Upadhyay, S., Rao, G.R., Sharma, M.K., Bhattacharya, B.K., Rao, V.K., Vijayaraghavan, R.: Immobilization of acetylcholineesterase-choline oxidase on a gold-platinum bimetallic nanoparticles modified glassy carbon electrode for the sensitive detection of organophosphate pesticides, carbamates and nerve agents. Biosens. Bioelectron. 25(4), 832-838 (2009)

31. Beleno Cabarcas, M.T., Stoytcheva, M., Zlatev, R., Montero, G., Velkova, Z., Gochev, V.: Chitosan nanocomposite modified OPH-based amperometric sensor for organophosphorus pesticides determination. Curr. Anal. Chem. 14(1), 75-82 (2018)
32. Xia, N., Gao, Y.: Carbon nanostructures for development of acetylcholinesterase electrochemical biosensors for determination of pesticides. Int. J. Electrochem. Sci. 10, 713-724 (2015)

33. Chen, D., Liu, Z., Fu, J., Guo, Y., Sun, X., Yang, Q., Wang, X.: Electrochemical acetylcholinesterase biosensor based on multiwalled carbon nanotubes/dicyclohexyl phthalate modified screenprinted electrode for detection of chlorpyrifos. J. Electroanal. Chem. 801, 185-191 (2017)

34. Zamfir, L.G., Rotariu, L., Bala, C.: A novel, sensitive, reusable and low potential acetylcholinesterase biosensor for chlorpyrifos based on 1-butyl-3-methylimidazolium tetrafluoroborate/ multiwalled carbon nanotubes gel. Biosens. Bioelectron. 26(8), 3692-3695 (2011)

35. Chen, D., Jiao, Y., Jia, H., Guo, Y., Sun, X., Wang, X., Xu, J.: Acetylcholinesterase biosensor for chlorpyrifos detection based on multi-walled carbon nanotubes- $\mathrm{SnO}_{2}$-chitosan nanocomposite modified screen-printed electrode. Int. J. Electrochem. Sci. 10, 10491-10501 (2015)

36. Kumaravel, A., Chandrasekaran, M.: Electrochemical determination of chlorpyrifos on a nano- $\mathrm{TiO}_{2} /$ cellulose acetate composite modified glassy carbon electrode. J. Agri. Food. Chem. 63(27), 6150-6156 (2015)

37. Yola, M.L., Atar, N.: A highly efficient nanomaterial with molecular imprinting polymer: carbon nitride nanotubes decorated with graphene quantum dots for sensitive electrochemical determination of chlorpyrifos. J. Electrochem. Soc. 164(6), 223-229 (2017)

38. Jiao, Y., Jia, H., Guo, Y., Zhang, H., Wang, Z., Sun, X., Zhao, J.: An ultrasensitive aptasensor for chlorpyrifos based on ordered mesoporous carbon/ferrocene hybrid multiwalled carbon nanotubes. RSC Adv. 6(63), 58541-58548 (2016)

39. Xu, G., Huo, D., Hou, C., Zhao, Y., Bao, J., Yang, M., Fa, H.: A regenerative and selective electrochemical aptasensor based on copper oxide nanoflowers-single walled carbon nanotubes nanocomposite for chlorpyrifos detection. Talanta 178, 1046-1052 (2018)

40. Pal, K., Maiti, U.N., Majumder, T.P., Debnath, S.C., Ghosh, S., Roy, S.K., Otón, J.M.: Switching of ferroelectric liquid crystal doped with cetyltrimethyl ammonium bromide assisted $\mathrm{CdS}$ nanostructures. Nanotechnology. 24(12), 125702 (2013)

41. Elkodous, M.A., El-Sayyad, G.S., Mohamed, A.E., Pal, K., Asthana, N., de Souza Junior, F.G., El-Batal, A.I: Layer-by-layer preparation and characterization of recyclable nanocomposite $\left(\mathrm{Co}_{x} \mathrm{Ni}_{1}-x \mathrm{Fe}_{2} \mathrm{O}_{4}, X=0.9 / \mathrm{SiO}_{2} / \mathrm{TiO}_{2}\right)$. J. Mater. Sci-Mater El. 30(9), 8312-8328 (2019)

42. Pal, K., Sajjadifar, S., Elkodous, M.A., Alli, Y.A., Gomes, F., Jeevanandam, J., Sigov, A.: Soft, self-assembly liquid crystalline nanocomposite for superior switching. Electron. Mater. Lett. 15(1), 84-101 (2019)

43. Pal, K., Elkodous, M.A., Mohan, M.M.: CdS nanowires encapsulated liquid crystal in-plane switching of LCD device. J. Mater. Sci-Mater. El. 29(12), 10301-10310 (2018)

44. Pal, K.: Hybrid Nanocomposites: Fundamentals, Synthesis, and Applications", CRC Press, 2019

45. Cai, Z., Yang, G.: Synthesis of polyindole and its evaluation for Li-ion battery applications. Synth. Met. 160, 1902-1905 (2010)

46. Döşlü, S.T., Mert, B.D., Yazıcı, B.: Polyindole top coat on $\mathrm{TiO}_{2}$ sol-gel films for corrosion protection of steel. Corros. Sci. 66, 51-58 (2013)

47. Tebyetekerwa, M., Yang, S., Peng, S., Xu, Z., Shao, W., Pan, D., Zhu, M.: Unveiling polyindole: freestanding As-electrospun polyindole nanofibers and polyindole/carbon nanotubes composites as enhanced electrodes for flexible all-solid-state supercapacitors. Electrochim. Acta 247, 400-409 (2017)

48. Zhou, W., Xu, J.: Progress in conjugated polyindoles: synthesis, polymerization mechanisms, properties, and applications. Polym. Rev. 57(2), 248-275 (2017) 
49. Rita, Mehtab, S., Zaidi, M.G.H., Singhal, K., Arya, B., Siddiqui, T.I.: Polyindole Based Nanocomposites and their Applications: A Review. Mat. Sci. Res. Ind. 16(2), 97-102 (2019)

50. Taylan, N.B., Sari, B., Unal, H.I.: Preparation of conducting poly(vinyl chloride)/polyindole composites and freestanding films via chemical polymerization. J. Polym. Sci. Pol. Phys. 48(12), 1290-1298 (2010)

51. Joshi, L., Prakash, R.: One-pot synthesis of Polyindole-Au nanocomposite and its nanoscale electrical properties. Mat. Lett. 65(19), 3016-3019 (2011)

52. Rajasudha, G., Nancy, A.P., Paramasivam, T., Boukos, N., Narayanan, V., Stephen, A.: Synthesis and characterization of polyindole-NiO-based composite polymer electrolyte with $\mathrm{LiClO}_{4}$. Int. J. Polym. Mater. 60(11), 877-892 (2011)

53. Kumar, A., Pandey, A.C., Prakash, R.: Electro-oxidation of formic acid using polyindole- $\mathrm{SnO}_{2}$ nanocomposite. Catal. Sci. Tech. 2(12), 2533-2538 (2012)

54. Ganesan, R., Dhinasekaran, D., Paramasivam, T., Boukos, N., Vengidusamy, N., Arumainathan, S.: Preparation and characterization of polyindole-iron oxide composite polymer electrolyte containing $\mathrm{LiClO}_{4}$. Polym. Plast. Technol. 51(3), 225-235 (2012)

55. Zhou, X., Chen, Q., Wang, A., Xu, J., Wu, S., Shen, J.: Bamboolike composites of $\mathrm{V}_{2} \mathrm{O}_{5}$ /polyindole and activated carbon cloth as electrodes for all-solid-state flexible asymmetric supercapacitors. ACS Appl. Mater. Interfaces. 8(6), 3776-3783 (2016)

56. Trung, V.Q., Huyen, D.N.: Synthesis, properties and application of polyindole/ $/ \mathrm{TiO}_{2}$ nanocomposites. J. Phy. Conf. Ser. 187(1), 012058 (2009)

57. He, J., Duffy, N.W., Pringle, J.M., Cheng, Y.B.: Conducting polymer and titanium carbide-based nanocomposites as efficient counter electrodes for dye-sensitized solar cells. Electrochim. Acta 105, 275-281 (2013)

58. Thirugnanasambandan, T., Pal, K., Sidhu, A., Elkodous, M.A., Prasath, H., Kulasekarapandian, K., Jeevanandam, J.: Aggrandize efficiency of ultra-thin silicon solar cell via topical clustering of silver nanoparticles. Nano-Struct. Nano-Objects 16, 224-233 (2018)

59. El-Nasser, S.A., Kim, S., Yoon, H., Toth, R., Pal, K., Bechelany, M.: Sodium-assisted $\mathrm{TiO}_{2}$ nanotube arrays of novel electrodes for photochemical sensing platform. Org. Electron. 76, 105443$105450(2020)$

60. Govindasamy, G., Pal, K., Elkodous, M. A., El-Sayyad, G.S., Gautam, K., Murugasan, P.: Growth dynamics of CBD-assisted CuS nanostructured thin-film: optical, dielectric and novel switchable device applications. J. Mater. Sci-Mater. El. 30(17), 16463-16477 (2019)

61. Nihmath, A.M., Ramesan, T.: Effect of hydroxylapatite nanoparticles on structural and electrical properties of ethylene propylene diene monomer rubber. J. Chem. Pharm. Sci. 38-44 (2016)

62. Mudila, H., Rana, S., Zaidi, M.G.H., Alam, S.: Polyindole/ graphene oxide nanocomposites: the novel material for electrochemical energy storage. Fuller. Nanotub. Car. N. 23(1), 20-26 (2015)

63. Mudila, H., Rana, S., Zaidi, M.G.: Supercritical $\mathrm{CO}_{2}$ aided polyindole-graphene nanocomposites for high power density electrode. Adv. Mater. Let. 8(3), 269-275 (2017)

64. Aziz, S.B., Kadir, M.F.Z., Abidin, Z.H.Z.: Structural, morphological and electrochemical impedance study of CS: LiTf based solid polymer electrolyte: reformulated arrhenius equation for ion transport study. Int. J. Electrochem. Sci. 11, 9228-9244 (2016)

65. Hoffmann, P., Galindo, H., Zambrano, G., Rincón, C., Prieto, P.: FTIR studies of tungsten carbide in bulk material and thin film samples. Mater. Char. 50(4-5), 255-259 (2003)

66. Wang, R.X., Fan, Y.J., Wang, L., Wu, L.N., Sun, S.N., Sun, S.G.: Pt nanocatalysts on a polyindole-functionalized carbon nanotube composite with high performance for methanol electrooxidation. J. Power Sources 287, 341-348 (2015)

67. Lee, S.J., Jeong, J.R., Shin, S.C., Kim, J.C., Chang, Y.H., Lee, K.H., Kim, J.D.: Magnetic enhancement of iron oxide nanoparticles encapsulated with poly (D, L-latide-co-glycolide). Colloid. Surf. A. Physiochem. Eng. Asp. 255(1-3), 19-25 (2005)

68. Radja, I., Djelad, H., Morallon, E., Benyoucef, A.: Characterization and electrochemical properties of conducting nanocomposites synthesized from $p$-anisidine and aniline with titanium carbide by chemical oxidative method. Synth. Met. 202, 25-32 (2015)

69. Doşlu, S.T., Mert, B.D., Yazıcı, B.: The electrochemical synthesis and corrosion behaviour of $\mathrm{TiO}_{2}$ /poly (indole-co-aniline) multilayer coating: experimental and theoretical approach. Arab. J. Chem. 11(1), 1-13 (2018)

70. Ramesan, M.T.: Fabrication and characterization of conducting nanomaterials composed of copper sulfide and polyindole.: Polym. Compos. 33(12), 2169-2176 (2012)

71. Cai, Z.J., Zhang, Q., Song, X.Y.: Improved electrochemical performance of polyindole/carbon nanotubes composite as electrode material for supercapacitors. Electron. Mat. Lett. 12(6), 830-840 (2016)

72. Elgrishi, N., Rountree, K.J., McCarthy, B.D., Rountree, E.S., Eisenhart, T.T., Dempsey, J.L.: A practical beginner's guide to cyclic voltammetry. J. Chem. Educ. 95(2), 197-206 (2017)

73. Ji, D., Liu, L., Li, S., Chen, C., Lu, Y., Wu, J., Liu, Q.: Smartphone-based cyclic voltammetry system with graphene modified screen printed electrodes for glucose detection. Biosens. Bioelectron. 98, 449-456 (2017)

74. Cannon, R.D.: Electron transfer reactions. Butterworth-Heinemann ISBN 0-408-10646-8 (2016)

Publisher's Note Springer Nature remains neutral with regard to jurisdictional claims in published maps and institutional affiliations. 